\title{
Implants and ethnocide: Learning from the cochlear implant controversy
}

Professor Robert Sparrow, Department of Philosophy, Monash University.

\section{WORKING PAPER ONLY}

A version of this paper appeared as:

Sparrow, R. "Implants and Ethnocide: Learning from the cochlear implant controversy," Disability and Society 25 (4): 455-466. Published Online First, doi: 10.1080/09687591003755849.

Please cite that version.

\section{Abstract}

This paper uses the fictional case of the 'Babel fish' to explore and illustrate the issues involved in the controversy about the use of cochlear implants in prelinguistically deaf children. Analysis of this controversy suggests that the development of genetic tests for deafness poses a serious threat to the continued flourishing of Deaf culture. I argue that the relationships between Deaf and hearing cultures that are revealed and constructed in debates about genetic testing are themselves deserving of ethical evaluation. Making good policy about genetic testing for deafness will require addressing questions in political philosophy and anthropology about the value of culture and also thinking hard about what sorts of experiences and achievements make a human life worthwhile.

\section{Keywords}

Cochlear implants; deafness; Deaf culture; ethics; genetic testing; PGD 


\section{Implants and ethnocide: Learning from the cochlear implant controversy}

In Douglas Adams' Hitchhiker's Guide to the Galaxy books, experienced hitchhikers make use of a remarkable invention - the 'Babel fish' - to assist them in their quest to see the Galaxy for less than 30 Altairian dollars a day (Adams 1979). When inserted into a person's ear, the Babel fish converts sound waves to brain waves thereby allowing its owner to understand the speech of the aliens they meet in their travels. In a characteristically jaded aside, Adams observes that, by making it possible for people from different cultures to understand each other, the Babel fish was responsible for more conflicts than any other invention in human history (Adams 1979, 50). Whether Adams' cynicism about the benefits of universal communication is justified or not, the 'Babel fish' turns out to be a useful imaginary device to allow us to understand the past and present controversy over the use of a medical device - the cochlear implant (Doe 2007). Consequently, thinking about the Babel fish may also assist us in thinking through the lessons of the cochlear implant controversy for the next challenge facing health policymakers and others concerned with the flourishing of deaf persons: the impact of genetic - and especially prenatal - testing for deafness.

Cochlear implants are medical devices designed to serve as a (partial) cure for certain types of deafness. They are distinguished from ordinary hearing aids by the fact that a portion of the device is surgically implanted into the middle ear of the recipient. This electrode stimulates nerve endings in the inner ear, allowing the implantee to perceive sound even in cases where the cause of deafness is dysfunction in the middle ear (Copeland and Pillsbury 2004; National Institute on Deafness and Other Communication Disorders 2008).

The development of the cochlear implant has been widely hailed as an example of medical progress, with its inventors receiving both public acclaim and financial rewards (Cochlear Limited 2006, 2007a, 2007b). People are therefore often surprised to learn that some people with the very condition that the implant is designed to cure greeted its invention with less enthusiasm (Barringer 1993; Doe 2007; Edwards 2005; Lane 1994; Lane and Grodin 1997). A significant portion of persons who are deaf understand themselves to be members of a minority cultural group ('Deaf culture') defined by their use of a signed language rather than individuals defined by a disability (Davis 2007; Dolnick 1993; Edwards 2005; Kauppinen 2006; Ladd 2002, 2006; Lane 1984, 1992, 1994; Lane and Bahan 1998a; Lane, Hoffmeister, and Bahan 1996; Mundy 2002; Padden and Humphries 1988). ${ }^{1}$ Members of various Deaf cultures have been especially critical of the implanting of cochlear implants into young deaf children (Barringer 1993; Lane and Bahan 1998a; National Association of the Deaf $1993^{2}$; Silver 1992) - a policy recommended by some in the medical profession in order to maximise the amount of time children have to get used to the implant and to learn to understand spoken language with it (Balknay, Hodges, and Goodman 1996; Balkany, Hodges, et al. 2001; Copeland and Pillsbury 2004).

\footnotetext{
${ }^{1}$ In what follows I will use 'capital D' Deaf to refer to this group and those who identify with it and 'lowercase d' deaf to refer to a hearing impairment and individuals who have such an impairment.

${ }^{2}$ The National Association of the Deaf famously revised its position statement on implants in 2000. The 2000 statement dropped the strong criticisms of the implant contained in the 1993 statement and instead emphasised the importance of parents making informed choices about implants after access to information which would include the experiences and perspectives of deaf persons.
} 
I should make it clear that I am not a member of Deaf culture and write here as a professional philosopher with research interests in the areas of multiculturalism and technologies of human enhancement. This article is therefore intended as a rational reconstruction and examination of an argument that might support claims that are often attributed to Deaf critics and not as advocacy for any particular position 'on behalf of' Deaf culture. In order to understand why some Deaf persons might object to the use of the cochlear implant in young children it helps to consider the following hypothetical scenario.

Imagine that you are a member of a minority linguistic community. You might think of yourself as a Native American in the United States, or as a non-Han ethnic minority in mainland China. In the not-too-distant past, members of your community have been imprisoned and tortured for daring to use their own language. Perhaps in response to the persecution they have faced in the past, members of your group tend to be fiercely proud of their cultural community. Despite this, members of your community face a number of profound social and economic disadvantages. It is harder for them to complete their education, find a job, or achieve the level of material success that is typical of members of the larger community. In part, this is because they are subject to morally pernicious discrimination from members of the dominant community. However, it is also the predictable consequence of being a minority surrounded by another culture whose members speak a different language.

These disadvantages seem especially disturbing when one considers the prospects of young children. Whereas older persons at least have the benefit of a cultural pride that affirms the values of the options they do have and discounts the value of the options they may have missed, young children appear to face only the prospect of a lifetime of disadvantage.

Government officials, doctors, and social workers have come up with a solution for the difficulties facing these children - they will provide all the young children born into this community with Babel fish. With the fish in their ear these children will have no problem understanding and speaking the majority language. As a result, they will be able to avoid the disadvantages facing those who speak only the minority language and they may even, if they wish, become fully integrated into, and members of, the majority community. Cynics amongst your community note that those who are most enthusiastic about the Babel fish are the doctors and researchers who produced them and who stand to profit substantially from the sale of each fish.

It must be said at this point that there are three important disanalogies between the scenario I have just described and the case of the cochlear implant: existing implants are nowhere near as effective as the imaginary 'Babel fish' at facilitating cross-cultural communication; deafness is arguably an organic dysfunction of the human organism regardless of whether it is also a condition or marker of cultural identity; and, the next generation of potential members of Deaf culture are born to parents who are members of another culture. These (greatly) complexify the issue in ways to which I will return in a moment.

In the meantime, I want to consider how one might feel about the government's policy in the scenario described above. The introduction of the Babel fish, even if motivated by concern for the opportunities available to the children, is likely to be extremely destructive to the culture of which they otherwise would have been members. While use of a Babel fish will not prevent these children from learning the language of their parents, it is likely to greatly reduce the probability that they will use it as their first language in adulthood or teach it to their children. Within two generations, then, the size of this minority culture is likely to be greatly reduced. As the community of people who use the language grows smaller, the opportunities to those within it grow fewer and the social disadvantages they face larger; this in turn increases the incentives for the next generation to learn the majority language and leave the 
minority culture behind. Over the longer term, this policy is likely to result in ethnocide - the destruction of a people's culture. This may appear as an attack on one's very identity in so far as this is connected with one's membership of a group with a historical past and an imagined future.

Not only is this policy likely to lead to the destruction of the culture, it also seems to involve a profound lack of respect for it. Thinking that the problems facing these children can be solved by providing them with a Babel fish undervalues what they are being encouraged to leave behind and what is threatened by their doing so. It is also insensitive to the fact that the source of the 'problem' is the relative size and social power of the two groups. If history had turned out differently it might have been the (current) majority cultural group that would be facing cultural extinction. A policy of assimilation based on the use of the Babel fish seems to claim as a right for the majority group a privilege it has as a result of historical accident.

Finally, there is something disturbing about the nature of the intervention - the physical alteration of the capacities of the bodies of children through the insertion of the Babel fish being used to promote integration into the majority culture and the role of scientists and doctors in advocating and facilitating it. A medical technology is here being used to advance a cultural agenda - a scenario that brings to mind some of the worst abuses of medical authority in the past.

Of course, with important caveats noted above, this is the likely story of the eventual impact of the cochlear implant. Deaf people use signed languages with all the complexity, structure, and communicative power of spoken languages (Vermeerbergen 2006). Deaf communities around the world have their own signed languages, as well as distinct cultural institutions such as Deaf clubs, churches, sporting groups, etc. (Edwards 2005; Goodstein 2006; Ladd 2002; Lane, Hoffmeister, and Bahan 1996). (Some) Deaf people are proud of their heritage and very conscious that, in the past, Deaf persons have been persecuted, imprisoned, and punished for using their own languages (Kauppinen 2006; Ladd 2002, 2006; Lane 1992, 1994). They are all-too-aware that a reduction of the numbers of people using signed language threatens the long-term survival of their culture. Some Deaf people have also objected strenuously to medical practitioners interfering in the bodies of young children in the service of a cultural ideal (Barringer 1993; Doe 2007, 4-5; Dolnick 1993; National Association of the Deaf 1993). It is no wonder then that some Deaf critics have been extremely critical of the use of cochlear implants in young children and have even accused advocates of implantation of complicity in ethnocide (Balknay, Hodges, and Goodman 1996, 748; Barringer 1993; Dolnick 1993; Edwards 2005; Lane and Grodin 1997; Silver 1992).

Before one might reach any conclusions about the ultimate strength of these objections, however, we need to return to consider the three disanalogies between the imaginary scenario I have been describing and the case of the cochlear implant, to which I referred above.

The first disanalogy derives from the fact that, despite dramatic improvements in the performances of the implants since they were first developed, cochlear implants are nowhere near being a real-world version of the imaginary 'Babel fish'. Outcomes after implantation vary widely, with the factors contributing to the development of high levels of speech perception and language use after implantation, other than age of implantation and mode of comunication prior to implantation, still poorly understood (Kubo, Iwaki, and Sasaki 2008; O'Donoghue, Nikolopoulos, and Archbold 2000; Taitelbaum-Swead et al. 2005). Some individuals who receive an implant may still need to rely on lip reading and clever guesswork in order to communicate with oral language users (Crouch 1997; Lane and Bahan 1998a). Moreover, there is a danger that parents of implanted children will fail to expose them to sign language after they have received an implant either because they believe this to be 
unnecessary because they expect their child to become fluent in spoken language using the implant or in the belief that exposure to sign will reduce the incentive for their children to work at the difficult task of learning to use the implant (Edwards 2005, 913). Children who do not learn to hear and speak using the implant may therefore end up deprived of the benefits that arise from exposure to sign language from an early age for deaf children (Lane and Bahan 1998a). As a result, the policy of promoting cochlear implantation in young children risks repeating the history of past policies of forced cultural integration wherein children were taken from one culture and prevented from learning its language but were also effectively denied the opportunity to assimilate into another culture (Wilson 1997). It may lead to children not becoming full members of Deaf or hearing cultures. This may result in children having fewer opportunities for a flourishing life than if they had remained members of Deaf culture.

The inability of implantation to guarantee full membership of the hearing culture greatly strengthens the case against cochlear implantation in young children (Crouch 1997). At the very least it shows that implantation must be accompanied by exposure to, and education in, signed language in order to insure against the possibility that the child will be left 'between' cultures (National Association of the Deaf 1993). If pursuing implantation reduces the exposure of children to signed languages and establishes a significant risk of their being left between cultures then this may establish an all-things-considered case against implantation. However, this argument against implantation relies on an empirical claim about the (lack of) effectiveness of the implants which is likely to weaken as the implants improve. At some point, this argument against implantation is likely to collapse entirely.

Perversely, the limitations of existing implants have also contributed significantly to reducing the controversy about cochlear implants. A number of accounts resolve the controversy by insisting that cochlear implants are not a threat to Deaf culture because implantees will continue to sign and to participate in the social life and institutions of the Deaf (Christiansen and Leigh 2006, 368; Doe 2007; Murray 2006; National Association of the Deaf 2000; Tucker 1998). However, while this may be true as a consequence of the limitations of the current (and previous) generation of implants, again it seems unlikely to remain true as the implants improve. In the long term, this 'pragmatic' solution to the controversy is therefore likely to have significant consequences for the survival of Deaf culture.

The second disanalogy concerns the fact that the limitations on the opportunities available to deaf children are not just the result of their being members of a minority of linguistic culture, they are also a consequence of these children suffering from an organic dysfunction of their hearing (Levy 2002a, 2007). It might therefore be argued that the entire analogy with forced cultural assimilation, which I have offered here, is misguided (Balkany, Hodges, and Goodman 1998; [Charles Berlin cited in] Barringer 1993; Davis 2007; Harris 2001; Tucker 1998). Cochlear implantation is justified not by the desire to expand the opportunities available to these children but in order to enable them to achieve 'normal species functioning' (Balknay, Hodges, and Goodman 1996).

However, this way of understanding the ethical issues around implantation in young children relies upon our being able to set out an account of 'normal species functioning' which grounds a distinction between the moral significance of illness and of suffering due to 'merely social' causes. It may well be possible to set out an account of normal human capacities or normal species functioning by drawing upon an essentially Aristotelian notion of the proper functioning of various organs and therefore of the capacities of a normal human organism (Cooper 2007, 569-70; Daniels 1985; Boorse 1975, 1977). What is more difficult is to explain the moral significance of any such account. That is, it is difficult to explain why 
'normal species functioning' should function as the justification of technological intervention where other barriers to the flourishing of individuals would not. Why should the fact that the limitations on the opportunities available to children in this particular case are due to organic dysfunction justify a policy that one would not think appropriate as a response to (for instance) racism or simply membership of a minority culture (Lane and Bahan 1998a)?

One possible answer is to argue that the reduction in welfare and/or loss of opportunities associated with less-than-normal human capacities is so extensive and so resistant to amelioration by anything other than medical approaches that normal health acquires moral significance by defining a baseline of opportunity which we should attempt to ensure is available to everyone (Daniels 1985). However, if the ultimate justification for a concern for normal species functioning refers to its effects on the welfare and/or range of worthwhile opportunities available to individuals such concern is vulnerable to the possibility that particular deviations from normal species functioning need not result in deprivations of these goods. Some Deaf persons may argue, plausibly, that they experience no negative impacts on their well-being or regrets due to the unavoidable loss of worthwhile opportunities from being deaf (Cooper 2007; Edwards 2005; Lane and Bahan 1998a). Moreover, it is clear that medical treatment is not the only way to ameliorate any negative impacts on well-being or restrictions on opportunity experienced by the Deaf by virtue of their circumstances.

Arguments for the normative force of this baseline are also undercut by the sensitivity of accounts of what is normal to historical and technological circumstances. One needs to be conscious of the fact that the idea of a 'normal human' body has often been deployed in the defence of discrimination and hierarchy in the past, around sex, race, and sexuality (Gould 1981; Conrad and Schneider 1980). Of course, this doesn't mean that a distinction between normal and abnormal capacities cannot be made, or does not apply in this case, but it should reduce one's confidence in it.

Finally, it is worth noting that Deaf culturalists need not deny that deafness is a departure from normal species functioning but only that this excludes it from also being a condition of cultural membership (Anstey 2002, 287) and that medical grounds for treatment must always trump concerns for culture (Levy 2002a). That is, even if one grants that deafness is an organic dysfunction and that it is normally appropriate to endorse the use of medical therapies to restore normal species functioning in cases of organic dysfunction it is still an open question as to whether or not it is appropriate in this case, given that deaf persons are clearly capable of enjoying an adequate range of worthwhile opportunities and a high level of wellbeing without medical treatment and given the cultural significance that deafness has for Deaf persons.

Obviously, there is (much) more to be said on this matter; reasons of space prevent me from doing so in this context. If one is inclined to adopt a medical model of deafness then the analogy between cochlear implants and the Babel fish will inevitably appear strained. However, what I have tried to show here is that establishing that deafness is a medical condition is not itself enough to invalidate the analogy.

There is a third disanalogy involved here. Early childhood deafness has a variety of causes and many of them do not involve inheritable conditions. Approximately $90 \%$ of children who are born deaf are born to parents who are not deaf (Balknay, Hodges, and Goodman 1996, 748). Providing these children with implants will not remove them from their culture because in ordinary cases one would say that 'their' culture was the culture of their parents (Balknay, Hodges, and Goodman 1996, 749). Indeed, where deaf children are born to hearing parents, the use of the cochlear implant may serve to facilitate their integration into their (parents') culture (Levy 2007, 140-1; Shannon 1998). In the short term, while implantation remains an 
unreliable method of achieving this integration, it may be possible to argue that the 'first' language of these children is a signed language and thus that they are appropriately thought of as potential members of the local Deaf culture (Barringer 1993; Dolnick 1993; Lane and Bahan 1998a, 304; 1998b, 312). However, even if one concedes this, it will still be the case that without a cochlear implant these children will not grow up as members of the culture of their parents, who will be denied the opportunity to transmit their culture to their children. The analogy with cultural assimilation of the children of a minority into a larger cultural group only seems entirely appropriate then, in the case where deaf children born to Deaf parents are encouraged or required to undergo implantation (Levy 2002a, 2007).

Nonetheless, it remains true that the use of cochlear implants in young children threatens Deaf cultures in a way which restricting their use does not threaten oral cultures. If deaf children of hearing parents grow up as members of Deaf culture, their parents will be deprived of the pleasures associated with sharing a culture with one's children and of the knowledge that their children will both enjoy the benefits of their culture and contribute to its flourishing in the future. However, the parents' culture itself will not be threatened; correspondingly, neither will the parents' capacity to feel confident that their culture will continue to flourish in the future. In contrast, the long-term survival of Deaf culture will be severely threatened if deaf children born to hearing parents grow up using spoken languages as a result of the widespread use of cochlear implants (Levy 2002a). Indeed, over several generations, the widespread use of the cochlear implant in young deaf children is likely to result in the extinction of Deaf culture (Lane and Bahan 1998a, 305).

This asymmetry between the circumstances of Deaf and hearing cultures in relation to deafness and implantation has important implications for the relationship between these cultures. Modern multicultural societies consist in different social groups living alongside one another as well as different individuals doing so. The interests that individuals have by virtue of membership in these groups can sometimes only be defended by policies that refer to relations between these groups. It is appropriate, then, for Deaf persons - and others sympathetic to their circumstances - to be concerned for the survival of their culture. The policy of encouraging pre-linguistic implantation in deaf children, especially if promoted by the government or by members of the majority (hearing) culture, represents an attack on Deaf culture. Members of Deaf culture may have cause to wonder why they should have any loyalty to a society that is dedicated to, or at least complicit with, the destruction of their culture (Lane and Bahan 1998a, 305). If one believes that the state in a liberal society should, as far as is possible, be neutral in relation to disputes between cultural groups (Kukathas 2003; Kymlicka 1992) then this may provide grounds to be concerned about this policy even if one is not a member of the culture under attack.

Importantly, recognising that there may be grounds for reservations about a policy of encouraging implantation arising out of a concern for relations between social groups does not itself establish that cochlear implants should not be made available to deaf children of hearing parents. The demands of the Deaf community that these children should grow to contribute to the flourishing of Deaf culture need to be placed against the desires of hearing parents of deaf children that their children should grow up within their culture (Anstey 2002; Levy 2002a, 2007; Shannon 1998). Resolving the conflict between these competing demands will require addressing some difficult questions in political philosophy regarding the status and moral significance of the claims of culture and their relative weight in relation to the moral demands of individuals (Davis 2007; Levy 2002a). It will also require theorising the relationship between parents, children, and the wider society. These are far larger tasks than I can hope to attempt here. My suspicion, though, is that the more implants come to offer a reliable mechanism of integrating deaf children into hearing society the more difficult it will 
be to resist the demands of hearing parents that they should be allowed to bring their children up in their own culture (Levy 2007). I have argued elsewhere that concern for relations between social groups might, however, justify restrictions on the sorts of medical research which should be funded by the state in multicultural societies (Sparrow 2005).

These three disanalogies therefore complexify but do not entirely invalidate the analogy between the case of the cochlear implant and the imaginary scenario involving the 'Babel fish' described above. It remains the case that this scenario may serve as a useful illustration of the issues surrounding cochlear implantation in young children. In particular, it serves to show why a policy of encouraging implantation might be accused of advocating ethnocide and why this policy might also be thought to demonstrate a profound lack of respect for Deaf culture. Whether or not these serious challenges to policy around the cochlear implant outweigh the increased opportunities implantation may offer to deaf children and, in particular, the opportunity they allow deaf children of hearing parents to grow up in their parents' culture, is, I believe, the most profound ethical question surrounding the use of the cochlear implant.

To a large degree, the cochlear implant controversy has been resolved in practice by the fact that large numbers of individual parents are making the decision to implant their children. Deaf institutions - and to some extent each local Deaf culture - are then faced with a choice between maintaining their opposition to implantation and thus risking becoming irrelevant to the needs of large numbers of children with hearing difficulties or welcoming implantees in the hope that they will come to identify with and contribute to Deaf culture despite their desire to also participate in hearing cultures (Murray 2006, 351-2). Deaf culture is uniquely vulnerable to being forced to make such a choice because in order to flourish it relies on the children of parents who are typically not members of the culture becoming members of Deaf culture. As I noted above, it seems likely that the inability of Deaf cultures to successfully resist the trend towards implantation will have significant implications for the nature of these cultures in the longer term.

Given the contemporary state of the debate it might be thought that the analysis I have provided here can only be of theoretical interest. I hope it is at least that. However, understanding precisely what was at stake in the cochlear implant controversy and the relative merits of the arguments therein may also help us to better understand the issues involved in the next challenge facing the Deaf community and others concerned with health care (and other) policy around deafness - the challenge of genetic testing.

Many forms of deafness are at least partially a result of genetic factors in the affected individuals. Scientists are making rapid progress in understanding the genetic causes of deafness, a task in which they have been greatly assisted by the completion of the Human Genome Project. As a consequence, it is now possible to test individuals for various genes associated with deafness. This may assist them in managing their health care. It may also assist them in making reproductive choices with the intention of minimising (or, for that matter, maximising - see Mundy 2002) the chance that their children will be born deaf. Genetic testing of adult individuals will allow them to determine the probability that they will conceive a deaf child in a particular relationship (Dillehay and Arnos 2006). Prenatal testing will allow them to determine if a particular pregnancy is likely to lead to the birth of a deaf child and to terminate the pregnancy if they don't like the answer. Finally, preimplantation genetic diagnosis will allow parents who are willing to conceive via IVF to choose whether they want a deaf child or not by selecting some embryos for implantation over others. Given that most prospective parents are not deaf and are likely to want hearing children, the prospect of widespread genetic testing poses a profound challenge to the continued existence of Deaf 
culture (Murray 2006).

The history of the cochlear implant controversy contains a number of lessons in relation to this challenge (Murray 2006).

The first - and most important - lesson relates to the urgency of the issues. As the history of the cochlear implant controversy shows very clearly, once a technology that offers apparent health benefits to children becomes available, most parents will decide to use it, regardless of subtle costs relating to longer-term considerations about how this might reshape the cultural environment in which their children grow up. The decision to make use of genetic information, once it becomes available, may be even easier to make than the decision to proceed with cochlear implantation (or not) because there is no danger of the child being left 'between' cultures as long as the parents choose a child like them. Thus, leaving the decision up to individuals or to couples is therefore likely to result in a predictable outcome - a dramatic decline in the number of children born deaf and thus of potential members of Deaf culture(s). If Deaf activists or policy makers want to avoid this outcome then it will be essential to contest the development of the technology or - given that it is arguably already too late to do this - at least the policy of making it available to individuals as a matter of routine (Murray 2006).

The second lesson that may be drawn from my analysis of the cochlear implant controversy is that this policy debate is - at least in part - a question of the relations between social groups and not simply an argument about the rights of individuals. It is the latter too, of course, but there are aspects of what is at stake in this debate that will be obscured if it is conducted entirely as a debate about individual liberty. Thus it is essential that one pays attention to the relationships between Deaf and hearing cultures that are both revealed and constructed in debates around genetic testing and considers the ethics and justice of those relations as well (Sparrow 2008). The force of arguments relating to these relations will depend on the extent to which deaf persons organise on the basis of a (Deaf) cultural identification and argue for respect and equality on that basis.

A third lesson of my analysis, then, is that the strength of possible Deaf objections to policies of routine genetic screening for deafness will depend in part on how one assesses arguments relating to the intrinsic worth of culture (Davis 2007). The hypothetical example of the Babel fish is extremely useful in this context, as it encourages us to imagine a scenario in which a culture is destroyed without any of its individual members being made any worse off. It seems clear to me that the world is a poorer place every time a culture disappears. However, whether the value of culture justifies turning away from policies that would benefit individuals but threaten cultures is a (much) more difficult question. Meeting the policy challenge of genetic testing, then, will require engaging in debates in anthropology and political philosophy about the value of culture as well as in debates in medical ethics.

However, finally, the history of the cochlear implant controversy shows that the argument that one should understand debates about funding for genetic testing for deafness as a contestation between cultural groups is most compelling if one doesn't think that deafness is also a medical condition that restricts the opportunities and experiences open to those who suffer it (Levy 2002b). The public's enthusiasm for the cochlear implant was arguably the result of the appeal of the idea of 'curing deafness' and restoring children (and others) to normal functioning. Similarly, given current understandings about health and disease, the choice between bringing a hearing or a deaf child into the world is naturally understood as a choice between a healthy child and a child suffering from a disease or disorder (Hintermair and Albertini 2005). Ideas about 'normal human' bodies are also likely to play a central role in debates about the use of preimplantation genetic diagnosis because of the potential that this 
technology might eventually be used to choose 'enhanced' and not just 'healthy' children (Silver 1999). The idea of the 'normal' has significant appeal as a way of distinguishing between legitimate therapeutic interventions and non-medical eugenic uses of this technology (Fukuyama 2003). Thus, despite the existence of the independent considerations about relations between hearing and Deaf cultures surveyed above, I suspect that it will ultimately prove impossible to resist the drive to test for and eliminate deafness without contesting the medical model of deafness. Developing good policy around genetic testing for deafness - and for other character traits - will require thinking hard about what sorts of experiences and achievements make a human life worthwhile and about the relationship between our ideas about what is normal and the availability of these goods in a world in which we have the power to shape the capacities of those we bring into the world (Hintermair and Albertini 2005; Parens 1995; Sandel 2004). Those who believe that there should be room for the Deaf in this world would therefore be well advised to play an active role in those debates (Dillehay and Arnos 2006).

As I observed at the outset of this paper, Douglas Adams quipped of the Babel fish that improved communication led to as much conflict as cooperation. The history of the cochlear implant certainly includes its fair share of conflict and controversy. My hope is that the analysis I have offered of the issues in this controversy might assist all involved to better understand what is at stake and why each side might hold the positions that they do. This in turn might improve the prospects of cooperation when it comes to the difficult matter of making policy about genetic testing for deafness. 


\section{REFERENCES}

Adams, D., 1979. The hitchhiker's guide to the galaxy. London: Pan Books.

Anstey, K. 2002. Are attempts to have impaired children justifiable? Journal of Medical Ethics 28: 286-8.

Balkany, T.J., A.V. Hodges and K.W. Goodman. 1996. Ethics of cochlear implantation in young children. Otolaryngology - Head and Neck Surgery 114: 748-55.

Balkany, T.J., A.V. Hodges, and K.W. Goodman. 1998. Additional comments: Ethics of cochlear implantation in young children. Otolaryngology - Head and Neck Surgery 119: 31213 .

Balkany, T.J., A.V. Hodges, R.T. Miyamoto, K. Gibbin, and O. Odabasi. 2001. Cochlear implants in children. Otolaryngologic Clinics of North America 34: 455-67.

Barringer, F. 1993. Pride in a soundless world: Deaf oppose a hearing aid. New York Times, May 16, A1.

Boorse, C. 1975. On the distinction between disease and illness. Philosophy and Public Affairs 5: 49-68.

Boorse, C. 1977. Health as a theoretical concept. Philosophy of Science 44: 542-73.

Christiansen, J.B., and I.W. Leigh. 2006 The dilemma of paediatric cochlear implants. In The deaf way II reader, ed. H. Goodstein, 363-9. Washington, DC: Gallaudet University Press.

Cochlear Limited. 2006. Cochlear Limited wins gold in New York.

http://www.cochlear.com/PDFs/Announcement_MDEA_June_06.pdf (accessed July 17, 2008).

Cochlear Limited. 2007a. Cochlear wins 2007 DHL Australian Exporter of the Year Award. http://www.cochlear.com/PDFs/Cochlear_Exporter_of_Year_Nov_2007.pdf (accessed July 17, 2008).

Cochlear Limited. 2007b. Annual Report 2007. Retrieved July 17, 2008, from http://www.cochlear.com/PDFs/AR07_Editorial_070921.pdf.

Conrad, P., and J.W. Schneider. 1980. Deviance and medicalization: From badness to sickness. St Louis, MO: Mosby.

Cooper, R. 2007. Can it be a good thing to be deaf? Journal of Medicine and Philosophy 32: 563-83.

Copeland, B.J., and H.C. Pillsbury. 2004. Cochlear implantation for the treatment of deafness. Annual Review of Medicine 55: 157-67.

Crouch, R.A. 1997. Letting the deaf be deaf: Reconsidering the use of cochlear implants in prelingually deaf children. Hastings Center Report 27, no. 4: 14-21.

Daniels, N. 1985. Just Health Care. New York: Cambridge University Press.

Davis, L.J. 2007. Deafness and the riddle of identity. The Chronicle of Higher Education 53, 
no. 19: B5-B8.

Dillehay, J., and K. Arnos. 2006. The impact of genetics research on the deaf community. In The deaf way II reader, ed. H. Goodstein, 370-5. Washington, DC: Gallaudet University Press.

Doe, L. 2007. Cochlear implants: Are they really a threat to the deaf community? Deaf Worlds 23: 1-17.

Dolnick, E. 1993. Deafness as culture. The Atlantic Monthly 272, no. 3: 37-53.

Edwards, R.A.R. 2005. Sound and fury; Or, much ado about nothing? Cochlear implants in historical perspective. The Journal of American History 92: 892-920.

Fukuyama, F. 2003. Our post-human future: consequences of the biotechnology revolution. London: Profile Books.

Goodstein, H. 2006. Preface. The deaf way II reader, xiii-xxii. Washington, DC: Gallaudet University Press.

Gould, S.J. 1981. The mismeasure of man. Harmondsworth, England: Penguin.

Harris, J. 2001. One principle and three fallacies of disability studies. Journal of Medical Ethics 27: 383-7.

Hintermair, M., and J.A. Albertini. 2005. Ethics, deafness, and new medical technologies. The Journal of Deaf Studies and Deaf Education 10: 184-92.

Kauppinen, L. 2006. Our inalienable rights: Global realisation of the human rights of deaf people. In The deaf way II reader, ed. H. Goodstein, 10-16. Washington, DC: Gallaudet University Press.

Kubo, T., T. Iwaki, and T. Sasaki. 2008. Auditory perception and speech production skills of children with cochlear implant assessed by means of questionnaire batteries. ORL 70: 224-8.

Kukathas, C. 2003. The liberal archipelago. Oxford: Oxford University Press.

Kymlicka, W. 1992. Liberal individualism and liberal neutrality. In Communitarianism and Individualism, ed. S. Avineri and A. De-Shalit, 165-85. Oxford: Oxford University Press.

Ladd, P. 2002. Emboldening the deaf nation. Deaf Worlds 18: 88-95.

Ladd, P. 2006. What is deafhood and why is it important? In The deaf way II reader, ed. H. Goodstein, 245-50. Washington, DC: Gallaudet University Press.

Lane, H. 1984. When the mind hears: A history of the deaf. New York: Random House.

Lane, H. 1992. The mask of benevolence: Disabling the deaf community. New York: Alfred Knopf.

Lane, H. 1994. The cochlear implant controversy. WFD News 2-3: 22-8.

Lane, H., and B. Bahan. 1998a. Ethics of cochlear implantation in young children: A review and reply from a deaf-world perspective. Otolaryngology - Head and Neck Surgery 119: 297- 
308.

Lane, H., and B. Bahan. 1998b. Reply to the review: Ethics of cochlear implantation in young children. Otolaryngology - Head and Neck Surgery 119: 309-12.

Lane, H., and M. Grodin. 1997. Ethical issues in cochlear implant surgery: An exploration into disease, disability, and the best interests of the child. Kennedy Institute of Ethics Journal 7: $231-51$.

Lane, H., R. Hoffmeister, and B. Bahan. 1996. A journey into the deaf-world. San Diego, CA: DawnSign Press.

Levy, N. 2002a. Reconsidering cochlear implants: The lessons of Martha's Vineyard. Bioethics 16: 134-53.

Levy, N. 2002b. Deafness, culture, and choice. Journal of Medical Ethics 28: 284-5.

Levy, N. 2007. Must publically funded research be culturally neutral? Virtual Mentor 9: 140 2.

Mundy, L. 2002. A world of their own. Washington Post Magazine, March 31, W22.

Murray, J.J. 2006. Genetics: A future peril facing the global deaf community. In The deaf way II reader, ed. H. Goodstein, 351-6. Washington, DC: Gallaudet University Press.

National Association of the Deaf. 1993. Cochlear implants: A position paper of the National Association of the Deaf. Silver Spring, MD: The National Association of the Deaf.

National Association of the Deaf. 2000. Cochlear implants: A position paper of the National Association of the Deaf. Silver Spring, MD: The National Association of the Deaf.

National Institute on Deafness and Other Communication Disorders. 2008. Cochlear implants. http://www.nidcd.nih.gov/health/hearing/coch.asp (accessed July 17, 2008).

O’Donoghue, G.M., T.P Nikolopoulos, and S.M Archbold. 2000. Determinants of speech perception in children after cochlear implantation. Lancet 356: 466-8.

Padden, C., and T. Humphries. 1988. Deaf in America: Voices from a culture. Cambridge, MA: Harvard University Press.

Parens, E. 1995. The goodness of fragility: On the prospect of genetic technologies aimed at the enhancement of human capabilities. Kennedy Institute of Ethics Journal 5: 141-3.

Sandel, M.J. 2004. The case against perfection: What's wrong with designer children, bionic athletes, and genetic engineering. The Atlantic Monthly 293, no. 3: 51-62.

Shannon, R.V. 1998. Review: The ethics of cochlear implantation in young children. Otolaryngology - Head and Neck Surgery 119: 308-9.

Silver, A. 1992. Cochlear implants: Sure-fire prescription for long-term disaster, TBC News 53: 4-5.

Silver, L.M. 1999. Remaking Eden: Cloning, genetic engineering and the future of human 
kind. London: Phoenix.

Sparrow, R. 2005. Defending deaf culture: The case of cochlear implants. The Journal of Political Philosophy 13: 135-52.

Sparrow, R. 2008. Genes, identity, and the expressivist critique. In The sorting society, ed. L. Skene and J. Thompson, 111-32. Cambridge: Cambridge University Press.

Taitelbaum-Swead, R., L. Kishon-Rabin, R. Kaplan-Neeman, C. Muchnik, J. Kronenberg, and M. Hildesheimer. 2005. Speech perception of children using Nucleus, Clarion, or Med-El cochlear implants. International Journal of Pediatric Otorhinolaryngology 69: 1675-83.

Tucker, B.P. 1998. Deaf culture, cochlear implants, and elective disability. Hastings Center Report 28, no. 4: 6-14.

Vermeerbergen, M. 2006. Past and current trends in sign language research. Language \& Communication 26: 168-92

Wilson, R. 1997. Bringing them home: Report of the national inquiry into the separation of Aboriginal and Torres Strait Islander children from their families. Sydney: Human Rights and Equal Opportunity Commission. 